\title{
MODIFIKASI PENGUNCI KEPALA LEPAS UNTUK MESIN BUBUT MAXIMAT V13
}

\author{
Intan Rahmayuni ${ }^{1}$, Arif Rahman ${ }^{2}$, Elvis Adril ${ }^{3}$, Yuli Yetri $^{4^{*}}$ \\ ${ }^{1}$ Program studi Teknik Manufaktur Jurusan Teknik Mesin, Politeknik Negeri Padang \\ 2,3,4Program studi Teknik Mesin Jurusan Teknik Mesin, Politeknik Negeri Padang \\ Jl.Kampus, Limau Manis, Kec. Pauh, Kota Padang 25163, Sumatera Barat, Indonesia \\ E-mail: intannuni62@gmail.com ${ }^{1}$,arifrahman@gmail.com ${ }^{2}$,elvis@pnp.ac.id ${ }^{3}$, yuliyetri@pnp.ac.id ${ }^{4}$
}

\begin{abstract}
Abstrak
Selama ini pengunci kepala lepas yang biasa digunakan adalah berbahan coran yang susah untuk didapat dan harganya yang cukup mahal, dan itu menjadi penghambat untuk menggantinya jika terjadi kerusakan atau hilangnya pengunci kepala lepas tersebut. Untuk itu modifikasi pun bisa dilakukan demi mempermudah pengunaan mesin ini, yang mana modifikasi pengunci kepala lepas pada mesin bubut karena desain yang sebelumnya mengalami kerusakan dan tidak bisa digunakan dengan sebagai mana mestinya dan juga membuat pengunci yang lebih efisien dan lebih baik dari yang sebelumnya. Berdasarkan kasus masalah yang dihadapi yaitu rancang bangun modifikasi pengunci kepala lepas pada mesin bubut maximat V13, pendekatan konsep yang digunakan adalah perencanaan produk dengan perencanaan simultan atau perencanaan dengan pendekatan proses produksi. Dengan pemilihan bahan dan perhitunghan bahan yang tepat maka target yang diinginkan akan bisa diraih dengan sempurna dan pengunaan akan sangat membantu dalam pengunaan kepala lepas pada mesin bubut. Memodifikasi pengunci kepala lepas pada mesin bubut maximat V13 ini berhasil dirancang untuk menggantikan pengunci kepala lepas mesin bubut yang sudah rusak karena berfungsi sebagaimana mestinya.
\end{abstract}

Kata kunci: Pengunci kepala lepas, kekuatan bahan, modifikasi

\begin{abstract}
During this time the tailstock off which is commonly used is made of castings which is difficult to obtain and the price is quite expensive, and it becomes on obstacle to replace it if there is damage or loss of locking the "tailstock". For modifying it can be done in order to facilitate the use of machine, which is the modification of the tailstock release on the lathe because the design was previously damage and cannot be used properly and also makes locking more efficient and better than before. Based on the problem cases faced which is the design and construction of a modified locking head on the maximat V13 lathe, the conceptual approach used is product planning by simultaneous planning or planning with a production process approach. With the right material selection and material calculation, the desired target will be achieved perfectly and the use will ber very helpful in the use of loose heads on the lathe.

Modifying the loose head lock on the maximat V13 lathe was successfully designed to replace the broken head lock of the lathe because it works as it should.
\end{abstract}

Keywords: tailstock lock, material strength, modification

\section{Pendahuluan}

Indonesia merupakan negara yang sedang berkembang yang cukup pesat dalam pembangunan. Sejalan dengan perkembangan yang sedemikian pesat di bidang mekanik tidak juga kalah ketinggalan dengan kemajuan teknologi saat ini. Sebagai mahasiswa yang mendalami ilmu teknik mesin, kita dituntut ikut serta berperan secara aktif dalam menunjang kemajuan itu dan lebih kreatif dalam merancang dan sekaligus mengeluarkan inovasi-inovasi yang berguna dan bermanfaat.

Dengan perkembangan Ilmu Pengetahuan dan Teknologi yang tumbuh dengan cepat tersebut akan mendorong manusia untuk dapat menciptakan suatu sistem yang dapat melindungi dirinya dari pengaruh lingkungan yang kurang menguntungkan. Semua itu 
juga terjadi dalam melakukan suatu pekerjaan dengan mengunakan mesin bubut ataupun mesin lainnya.

Mesin bubut merupakan salah satu mesin yang sangat berpengaruh dalam keteknikan dan perbengkelan karena bisa mengerjakan yang berupa benda kerja berbentuk silinder ataupun pipa pejal dan pipa dengan ukuran yang menyesuaikan dengan ukuran mesin tersebut [1]. Dalam perkembangan ilmu pengetahuan mesin bubut telah mengalami proses permodrenisasi yang sangat cepat tapi hal itu tidak menguragi daya pengunaan mesin yang boleh dibilang semi automatik ini. Mesin bubut ini tidak hanya bisa dioperasikan dengan manual tapi pada kondisi tertentu bisa otomatis dan juga pembuatan ulir dengan ukuran yang telah kita tentukan.

Modifikasipun bisa dilakukan demi memudahkan pengunaan mesin ini, yakni modifikasi pengunci kepala lepas pada mesin bubut karena desain yang sebelumnya mengalami kerusakan dan tidak bisa digunakan dengan sebagai mana mestinya dan juga membuat pengunci yang lebih efisien dan lebih baik dari yang sebelumnya. Dengan pemilihan bahan dan perhitungan bahan yang tepat maka target yang diinginkan akan bisa diraih dengan sempurna dan pengunaan akan sangat membantu dalam pengunaan kepala lepas pada mesin bubut.

\section{Metode}

\subsection{Bahan dan Alat}

Bahan yang digunakan untuk membuat modifikasi ini adalah besi padu St.37 dengan dimensi \pm 122 × $96 \times 35$ mm yang banyak di jual di pasaran. Adapun alat yang digunakan dalam pengamatan data ini adalah mesin bubut dan komponen-komponennya yang ada di bengkel mekanik jurusan teknik mesin.

\subsection{Waktu dan Tempat}

Tempat untuk melakukan pengambilan data yaitu di Bengkel Mekanik Jurusan Teknik Mesin, Politeknik Negeri Padang, pada bulan November 2018.

Berdasarkan kasus masalah yang dihadapi yaitu rancang bangun modifikasi pengunci kepala lepas pada mesin bubut maximat V13, pendekatan konsep yang digunakan adalah perencanaan produk dengan perencanaan simultan atau perencanaan dengan pendekatan proses produksi. Konsep perencanaan simultan terdapat empat elemen utama, yaitu: fungsi, bentuk, material, dan produksi [2]. Fungsi merupakan elemen penting diantara keempat elemen perencanaan simultan. Bentuk harus disesuaikan juga dengan keadaan [3]. Material menentukan bagaimana kualitas mesin yang akan dibuat dan ketahanannya [4]. Setelah semuanya terdesain dengan baik, produksi baru bisa berjalan, yang diagram alir kerja dapat dilihat pada Gambar 1.

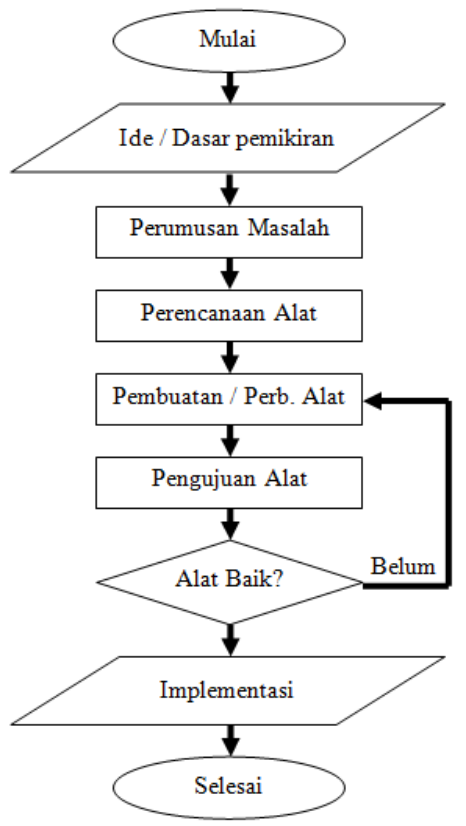

Gambar 1. Diagram alir dari langkah-langkah Perancangan Produk

\subsection{Pemilihan Bahan}

Hal-hal yang harus diperhatikan dalam pemilihan bahan antara lain:

1. Material yang digunakan harus mudah didapat

2. Material harus sesuai dengan fungsinya

3. Efisiensi dari bahan yang digunakan

4. Harga terjangkau

5. Keindahan dari konstruksi bahan

\section{Hasil dan Pembahasan}

Konsep perencanaan simultan terdapat empat elemen utama, yaitu: fungsi, bentuk, material, dan produksi untuk menganalisa 4 elemen tersebut perlu dicari melalui perhitungan sebagai berikut:

\subsection{Elemen Bentuk dan Material (Gaya yang Mampu ditahan Desain Baru Pengunci Kepala Lepas )}

Perancangan pengunci kepala lepas dari segi bentuk dan material tentu saja harus mampu menahan berbagai beban yang akan diterima kepala lepas saat beroperasi,oleh sebab itu harus diketahui maximum pembebananya dengan cara perhitungan sebagai berikut: Berikut merupakan 
konstriksi modifikas baru pengunci kepala lepas dapat dilihat pada Gambar 2.
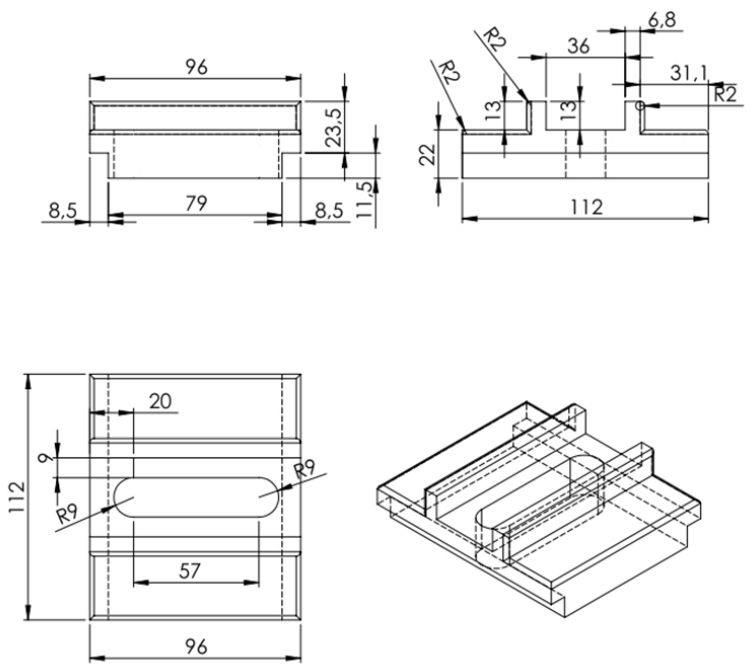

Gambar 2. Konstruksi Modifikasi Baru Pengunci Kepala Lepas [5].

Diket : $\quad b=36$

$$
1=96
$$

Luas daerah yang kosong $=1280,34$

Dari konstruksi modifikasi baru pengunci kepala lepas dapat dihasilkan persamaan statika sebagai berikut:

1. Tegangan geser :

$$
\sigma_{\text {geser }}=\frac{F}{A}
$$

dengan $\sigma$ adalah tegangan geser $\left(\mathrm{N} / \mathrm{mm}^{2}\right)$. F merupakan gaya yang diterapkan. Dan A merupakan luascross-sectional bahan dengan luas paralel dengan vektor gaya yang diterapkan[10].

$$
\begin{aligned}
\sigma \text { _geser } & =0,75 \times \sigma \text { p patah } \\
& =0,75 \times 362,97 \\
& =272,27 \mathrm{~N} / \mathrm{mm} 2
\end{aligned}
$$

$\sigma \_(\text {geser ijin })=272,27 / 4=68,06$

$$
\sigma_{\text {geser }}=\frac{F}{A}
$$

$$
\begin{aligned}
68,06 & =\frac{F}{A} \\
68,06 & =\frac{F}{36 x 96-1280,34}
\end{aligned}
$$

$\mathrm{F}=68,06 \times 36 \times 96-1280,34=233.935,02 \mathrm{~N}$
2. Momen Inersia

$\mathrm{I}=1 / 12 \times \mathrm{b} \times(\mathrm{h})^{3}$

dengan I adalah momen inersia. b merupakan lebar(mm) yang diterapkan. Sedangkan h merupakan panjang/tinggi(mm) bahan yang diterapkan.

$$
\begin{aligned}
\mathrm{I} & =1 / 12 \times \mathrm{b} \times(\mathrm{h})^{3} \\
& =1 / 12 \times 36 \times(96)^{3} \\
& =2.654 .208
\end{aligned}
$$

Tegangan Bengkok :

$$
\sigma_{\text {bengkok }}=\frac{M B}{W B}
$$

dengan $\sigma \mathrm{b}$ adalah tegangan bengkok bahan $\left(\mathrm{kg} / \mathrm{mm}^{2}\right)$. Mb Merupakan Momen bengkok yang terjadi pada lengan $(\mathrm{kg} / \mathrm{mm})$. Sedangkan $\mathrm{Wb}$ merupakan momen tahan bengkok bahan $\left(\mathrm{mm}^{3}\right)$ [7]. Dapat dilihat pada Gambar 3.

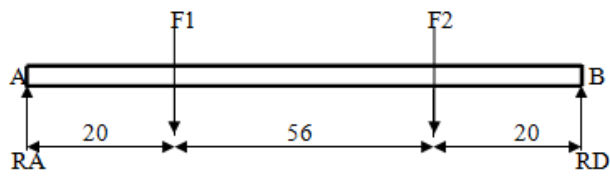

Gambar 3. Diagram Benda Bebas

$$
\begin{aligned}
& \mathrm{F} 1=\mathrm{F} 2=233.935,02 \\
& \sum \mathrm{MA}=0 \\
& \mathrm{~F} 1 \times 20+\mathrm{F} 2 \times 76=\mathrm{RB} 96 \\
& 233.935,02 \times 20+233.935,02 \times 76=96 \\
& \mathrm{RB} \\
& \begin{aligned}
4.678 .700,4+17.779 .062=96 \mathrm{RB} \\
\frac{22.457 .762}{96}=R B \\
\mathrm{RB}=233.935,02 \mathrm{~N} \\
\sum \mathrm{Fy}=0 \\
\mathrm{RA}=\mathrm{F} 1=\mathrm{F} 2-\mathrm{RB} \\
=233.935,02+233.935,02-233.935,02 \\
=233.935,02 \mathrm{~N}
\end{aligned}
\end{aligned}
$$




$$
\begin{aligned}
\mathrm{Mb}= & \text { RA } 20 \\
& =233.935,02 \times 20 \\
& =4.678 .700,4 \mathrm{Nmm}
\end{aligned}
$$

Momen di sepanjang lengan menjelaskan tegangan bengkok $(\sigma b)$ seperti ditunjukkan dalam persamaan berikut:

$$
\sigma_{\text {bengkok }}=\frac{M B}{W B}
$$

dengan $\sigma \mathrm{b}$ adalah tegangan bengkok bahan $\left(\mathrm{kg} / \mathrm{mm}^{2}\right)$. Mb Merupakan momen bengkok yang terjadi pada lengan $(\mathrm{kg} / \mathrm{mm})$. Sedangkan $\mathrm{Wb}$ merupakan momen tahan bengkok bahan $\left(\mathrm{mm}^{3}\right)$ [7]. Dapat dilihat pada Gambar 4.

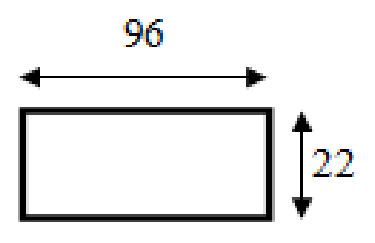

Gambar 4. Dimensi dari samping

Dari gambar 4 tersebut dapat dihasilkan persamaan statika sebagai berikut:

$$
\mathrm{Wb}=\frac{1}{6} \times \mathrm{b} h^{2}
$$

dengan $\mathrm{Wb}$ adalah Momen tahan bengkok bahan $\left(\mathrm{mm}^{3}\right)$. b Merupakan panjang yang yang diterapkan pada benda (mm). Sedangkan $\mathrm{h}$ panjang benda (mm) [7].

$$
\begin{aligned}
& \begin{aligned}
\mathrm{Wb} & =\frac{1}{6} \times 96(22)^{2} \\
& =16 \times 484 \\
& =7.744 \mathrm{~mm}^{3}
\end{aligned} \\
& \sigma_{\text {bengkok }}=\frac{4.678 .700,4 \mathrm{Nmm}^{\mathrm{g}}}{7.744 \mathrm{~mm}^{\mathrm{g}}}
\end{aligned}
$$

$$
=604,17^{\mathrm{N}} / \mathrm{mm}
$$

\subsection{Elemen Proses (Menentukan Putaran Mesin} Milling yang Digunakan untuk Membuat Pengunci Kepala Lepas)

Pada proses perlu mengatur putaran mesin (rpm) sesuai dengan diameter benda kerja yang sedang dikerjakan [9]. Penentuan putaran mesin milling yang digunakan menggunakan rumus berikut:

$$
\mathrm{Vc}=\frac{d \mathrm{xn}}{100 \mathrm{C}}
$$

Dimana Vc adalah kecepatan potong ( $\mathrm{mm} / \mathrm{menit}), \mathrm{d}$ menunjukan diameter pisau ( $\mathrm{mm})$, $\mathrm{n}$ adalah putaran spindle (rpm)[8]. Dengan tujuan menentukan $\mathrm{n}$ (putaran spindle) menggunakan rumus dasar diatas dapat disempurnakan menjadi berikut:

$$
\mathrm{n}=\frac{\text { Vex } 1.000}{n x d}
$$

keterangan :

Vc $($ Velocity of cutting $)=22$

$$
\mathrm{n}=\frac{22}{7}
$$

$$
\begin{aligned}
& \mathrm{d}(\text { diameter cutter })=16 \\
& \mathrm{n}=\frac{V c x 1.000}{\frac{32}{7} \times 16} \\
& \mathrm{n}=\frac{22 \times 1.000}{\frac{22}{7} \times 16} \\
& \mathrm{n}=\frac{7.000}{20} \\
& \mathrm{n}=437,4 \mathrm{Rpm}
\end{aligned}
$$


3.3 Elemen Fungsi (Tegangan Tarik dan

Tegangan Geser Akibat Pengencangan Baut Pengunci Kepala Lepas pada Mesin Bubut Maximat V13)

Dari segi fungsi pada perancangan konstruksi modifikasi baru pengunci kepala lepas ada beberapa hal yang harus dipertimbangkan diantaranya tegangan yang diterima oleh pengunci kepala lepas saat diberi perlakuan pengencangan baut penguncinya, diantaranya:

1. Tegangan Tarik

$$
\tau t=\frac{4 \cdot W}{\pi \cdot d i^{2}}
$$

Dimana $\mathrm{W}$ adalah beban $(\mathrm{kg})$ yang diterima pada kepala lepas sedangkan di adalah diameterr inti ulir (mm), dan $\tau t$ adalah tegangan tarik $\left(\mathrm{kg} / \mathrm{mm}^{2}\right)$ yang terjadi saat pengencangan.

Diketahui:

Baut M 16 x 2

de $=14,701 \mathrm{~mm}$

$\mathrm{di}=13,83 \mathrm{~mm}$

$\mathrm{W}=\mathrm{F}=100 \mathrm{~kg}$

Jawab:

$$
\begin{aligned}
& \tau t=\frac{4 \cdot 100}{\pi \cdot 12 \cdot 3 \mathrm{~g}^{2}} \\
& \tau t=0,711 \mathrm{Kg} / \mathrm{mm}^{2}
\end{aligned}
$$

2. Tegangan Geser

$$
\tau g=\frac{4 . W}{\pi \cdot d e^{2} \cdot m}
$$

$$
\begin{aligned}
\text { dengan } & \text { : } \\
\mathrm{W} & =\text { Beban }(\mathrm{kg}) \\
\mathrm{de} & =\text { Diameter efektif } / \text { rata }- \text { rata ulir }(\mathrm{mm}) \\
\tau g & =\text { Tegangan geser }\left(\mathrm{kg} / \mathrm{mm}^{2}\right) \\
\mathrm{n} & =\text { Jumlah Baut }{ }^{[4]}
\end{aligned}
$$

Diketahui :

Baut M 16 x 2

$\mathrm{de}=14,701 \mathrm{~mm}$

$\mathrm{W}=\mathrm{F}=100 \mathrm{~kg}$

Jawab:

$$
\begin{aligned}
& \tau g=\frac{4 \cdot 100}{\pi \cdot 14,701^{2} \cdot 1} \\
& \tau g=0,589 \mathrm{Kg} / \mathrm{mm}^{2}
\end{aligned}
$$

\section{Analisa Pengujian}

Berdasarkan metode yang digunakan diperoleh data sebagai berikut:

1. Elemen Bentuk dan Material

Perhitungan kekuatan didasarkan pada tegangan normal yang dapat ditanggung oleh design baru pengunci kepala lepas yang menggunakan material St-37 didapatkan hasil sebagai berikut :

Tegangan geser $(\mathrm{F})=233.935,02 \mathrm{~N}$

Momen Inersia $=2.654 .208$

Tegangan Bengkok $=604,17^{N} / \mathrm{mm}$

2. Elemen Proses

Putaran mesin diatur berdasarkan diameter benda kerja yang didapat dari hasil perhitungan, yaitu :

$\mathrm{n}=437,4 \mathrm{Rpm}$

3. Elemen Fungsi

Tegangan yang diterima oleh pengunci kepala lepas saat diberi perlakuan pengencangan baut pengunci, didapatkan hasil berdasarkan hasil perhitungan, yaitu:

Tegangan Tarik $t t=0,711 \mathrm{Kg} / \mathrm{mm}^{2}$

Tegangan Geser $\tau g=0,589 \mathrm{Kg} / \mathrm{mm}^{2}$

\section{Kesimpulan}

Setelah dilakukan proses perancangan melalui beberapa tahapan maka dapat diambil kesimpulan, sebagai berikut: 
1. Memodifikasi pengunci kepala lepas pada mesin bubut maximat V13 ini berhasil dirancang untuk menggantikan pengunci kepala lepas mesin bubut yang sudah rusak.

2. Data-data yang didapat dari komponen perancangan yaitu :

a. Gaya yang mampu ditahan komponen ini adalah 233.935,02 N.

b. Bahan yang digunakan dalam pembuatan komponen adalah ST. 37.

c. Dimensi dari komponen ini adalah 112 $\mathrm{mm}$ x $96 \mathrm{~mm}$ x $35 \mathrm{~mm}$.

3. Komponen merupakan salah satu bagian penting pada mesin bubut, dimana komponen berfungsi untuk mengunci kepala lepas agar tidak bergerak pada saat pengoperasian mesin bubut.

\section{Ucapan Terima Kasih}

Kepada kedua orang tua, bapak Elvis Adril, dan ibuk Yuli Yetri, yang telah memberikan dukungan dalam menyusun artikel ini. Serta seluruh rekan-rekan di Jurusan Teknik Mesin angkatan 2017 khususnya Teknik Manufaktur yang telah banyak membantu penulis dalam penyusunanan artikel ini.

\section{Referensi}

[1] Sato. Takeshi, "Menggambar Mesin Menurut Standar ISO”, Jakarta: Pradyana Paramita, 1990.

[2] Sularso, "Dasar Perencanaan Dan Pemilihan Elemen Mesin Edisi Ke-6", Jakarta: Pradyana Paramita, 1987.

[3] R.S Khurni. J.K Gupta, “A Text Book of Machine Deasign”, New Delhi, 1982.

[4] Sonawan. Hery, "Perancangan Elemen Mesin", Bandung: Alfabeta, 2010.

[5] Warren J. Luzadder, "Menggambar Teknik", Surabaya: Erlangga, 1981.

[6] Suratman. M dan Ir. Ohan Junana, "Menggambar Teknik Mesin Dengan Standar ISO. Bandung: Pustaka, 2000.

[7] Sanda, "Analisa Dimensi Lengan Pada Model Rancangan Renograf Thyroid Uptake Terpadu", Volume 12 (hlm.30-37), 2015.

[8] Yudhyadi. Rachmanto dan Ramadan, "Optimasi parameter permesinan terhadap waktu proses pada pemrograman CNC", Volume 6 (hlm.38-50),2016.
[9] Hadimi, "Atur putaran mesin (rpm) sesuai dengan diameter benda kerja yang sedang dikerjakan", Volume 11(hlm.18-28), 2008.

[10]Naharuddin, AlimuddinSam dan Nugraha Candra, "Kekuatan Tarik dan Bending Sambungan Las Pada Material Baja SM 490 Dengan Metode Pengalasan SMAW dan SAW", Volume 6 (hlm.550-555), 2015. 